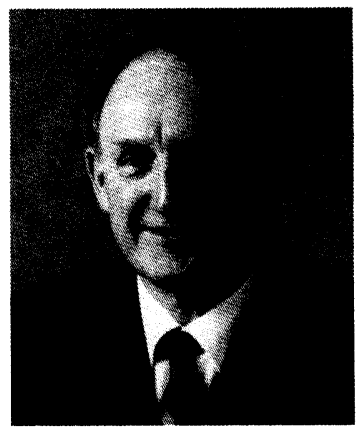

\section{Chinese Optical Society}

In September 1991 an agreement was reached between SPIE-The International Society for Optical Engineering and the Chinese Optical Society in which SPIE agreed to publish selected papers submitted by the editor of Acta Optica Sinica (AOS) in Optical Engineering. These papers are submitted by the editor of Acta Optica Sinica to me as editor of Optical Engineering. The papers are then put through the same peer-review process as all other papers submitted to Optical Engineering. The only difference you will see in the published AOS paper is the publication footnote that reads "... submitted by Acta Optica Sinica ...." As part of the arrangement, we also receive submissions from the editor of the Journal of Infrared and Millimeter Waves (JIRMW). Papers submitted and accepted by Optical Engineering will not be published in AOS or JRMW.

The editor(s) in China are responsible under the agreement for:

- identifying appropriate original engineering papers

- inviting Chinese authors to submit their papers to Optical Engineering

- arranging for Chinese authors to write extensions to their papers to meet the conventions of our journal

- arranging English translations, if required

- ensuring that the manuscripts and artwork are of appropriate quality

- explaining and mediating changes required by the editor and reviewers with the Chinese authors.

For our part, the Optical Engineering staff provides editorial support, in particular, help in bringing the translations up to the standard of Optical Engineering.

\section{Chinese Papers}

Under the agreement discussed above with AOS and JIRMW, I have received 41 papers so far. The current status of these papers is as follows:

$\begin{array}{lr}\text { Accepted for publication } & 12 \\ \text { Rejected } & 12 \\ \text { In revision } & 10 \\ \text { In review } & 6 \\ \text { Closed } & 1 \\ \text { Total } & 41\end{array}$

We are pleased to be publishing the first five of these papers in this issue of Optical Engineering.

The staff of Optical Engineering and I provide, to the best of our ability, the editorial support necessary for Chinese and other authors whose first language is not English. However, I am very pleased to report that the members of The Photonics Society of Chinese-Americans have agreed to provide editorial assistance for manuscripts received from China. They have formed an Optical Engineering Chinese Manuscript Editorial Committee under the able chair of Dr. Hua-Kuang Liu, and have provided me with a list of committee members who have volunteered to be active in this work. We will acknowledge their help on a paper with a notation in its publication footnote, but I would like to take this opportunity to thank them here.

As an international journal, Optical Engineering looks forward to publishing the work of our colleagues in China as well as others from around the world.

Brian J. Thompson

Editor 
April 1993

Emerging Optoelectronic Technologies

Vijai K. Tripathi

Oregon State Univeristy

Dept. of Electrical and Computer Eng.

ECE Building 220

Corvallis, Oregon 97331-3211

503/737-3617 • 503/737-1300 FAX

June 1993

From Numerical to Symbolic Image Processing: Systems \& Applications

G. Vernazza

Dipartimento di Ingegneria Biofisica ed Elettronica

Universita degli Studi di Genova

Via Opera Pia, 11a

16145 Genova, Italy

+39 10 353-2755 - +39 10 353-2777 FAX

Phase Contrast Microscopy

Maksymilian Pluta

Institute of Applied Optics

ul. Kamionkowska 18

03-805 Warszawa, Poland

$4822184405 \cdot 4822133265$ FAX

July 1993

Visual Communication and Image

Processing IV

Cheng-Tie Chen

Bellore

445 South St.

Morristown, NJ 07962

201/829-5151 • 201/829-5884 FAX

Hsueh-Ming Hang

Center for Telecommunication Research

National Chiao-Tung University

Hsinchu, Taiwan

$+886 / 35-712121 \times 3298 \bullet+886 / 35-723283$

FAX

Kou-Hu Tzou

COMSAT Labs.

22300 Comsat Drive

Clarksburg, MD 20871

301/428-4663 • 301/428-7747 FAX

September 1993

Optical Science and Engineering in Canada

C.P. Grover

National Research Council

Institute for National Measurement Standards

Ottawa, Canada K1A OR6

613/993-2098 • 613/952-1394 FAX

Optical Engineering in Hungary

Tivadar Lippenyi

HUNGOPTIKA

Tartsay u.24

Budapest H-1120, Hungary

3611563985 • 3611563985 FAX

Zoltan Fuzessy

Technical Univ. Budapest

Department of Physics

Balazs Bela u.36.IV.8.

Budapest H-1094, Hungary

$3611666361 \cdot 3611666808$ FAX

\section{October 1993}

Microlithography

James R. Sheats

Hewlett-Packard Company

2500 Deer Creek Road

Palo Alto, CA 94304-1392

415/857-5987 • 415/857-6241 FAX
November 1993

Acquisition, Tracking, and Pointing

Mohammed A. Karim

University of Dayton

Center for Electro-Optics

300 College Park

Dayton, Ohio 45469-0227

513/229-2241 • 513/229-3433

Manuscripts due April 1, 1993.

\section{December 1993}

Magnetospheric Imagery and

Atmospheric Remote Sensing

Supriya Chakrabarti

Boston University

Center for Space Physics

725 Commonwealth Avenue

Boston, MA 02215

E-mail: supo@bu-ast.bu.edu

617/353-5990 • 617/353-6463 FAX

Manuscripts due May 1, 1993.

\section{January 1994}

Infrared Technology

Marija S. Scholl

Alenlea Associates

P.O. Box 27408

Tempe, AZ 85285-7408

E-mail: msscholl@aol.com

602/491-7814

Manuscripts due May 1, 1993.

February 1994

Optical Interconnects and Packaging

Sing Lee

University of Califormia/San Diego

E\&CE Department

La Jolla, CA 92093-0407

619/534-2413 • 619/534-1225 FAX

Manuscripts due July 1, 1993.

\section{March 1994}

High Heat Flux Optical Engineering

Ali M. Khounsary

Argonne National Laboratory

Advanced Photon Source, APS 362

Argonne, Il 60439

708/252-3384 - 708/252-3222 FAX

Manuscripts due Aug. 1, 1993.

\section{April 1994}

Optical Pattern Recognition

Joseph L. Homer

Rome Laboratory

EROP

Hanscom AFB, MA 01731-5000

$617 / 377-3841 \cdot 617 / 377-5041$ FAX

Bahram Javidi

University of Connecticut

School of Engineering

Department of Electrical and Systems Engineering

Room 312, U-157

260 Glenbrook Road

Storrs, CT 06269-3157

203/486-4816 • 203/486-3789 FAX

Manuscripts due Sep. 1, 1993.
May 1994

Semiconductor Infrared Detectors

Antoni Rogalski

Institute of Technical Physics

Military Academy of Technology

Kaliskiego 2

00-489 Warsaw, Poland

$4822362109 \cdot 4822362254$ or

4822120757 FAX

Manuscripts due Oct. 1, 1993.

June 1994

Optical Science \& Engineering in India

Rajpal S. Sirohi

Indian Institute of Technology

Applied Optics Laboratory

Physics Department

Madras-600 036, India

044-2351365 ext. 221 • 044-2350509 FAX

Manuscripts due Nov. 1, 1993.

July 1994

Adaptive Wavelet Transforms

Harold H. Szu

U.S. Navy

Naval Surface Warfare Center

Code R44

10901 New Hampshire Avenue

Silver Springs, MD 20903-5000

301/394-3097 • 301/394-3923 FAX

Manuscripts due Dec. 1, 1993.

August 1994

Digital Image Recovery and Synthesis

Paul S. Idell

Air Force Phillips Lab.

PL/GPOA

390 B Great Road, \#18

Acton, MA 01720

612/377-3663 - 617/377-3661 FAX

Manuscripts due Dec. 1, 1993.

September 1994

Optics in South Africa

Hannes Markusse

ELOPTRO

Institute of Atomic Physics

P.O. Box 869

Kempton Park 1620, South Africa

Maurice W. McDowell

CSIR/Production Technology Div.

Productiontek

P.O. Box 395

Pretoria 0001, South Africa

$27128413418 \cdot 27128412131$ FAX

Manuscripts due Jan. 1, 1994.

October 1994

Optics in Russia

V. Ya. Panchenko

Scientific Research Center for Technological Lasers

Russia Academy of Sciences

B-333, Gubkina, 3

117971 Moscow, Russia

E-mail: ilc@compnet.npimsu.msk.su

(095)135-54-30 • (095)334-02-01 FAX

Manuscripts due March 1, 1994. 